\title{
ANALYSIS OF DERMATOLOGY LIFE QUALITY INDEX IN DERMATOPHYTOSIS
}

\author{
Anushree Khanvte', Karla Faleiro², Varadraj Pai ${ }^{3}$ \\ 1 1Junior Resident, Department of Skin and VD, Goa Medical College, Bambolim, Goa, India. \\ 2Junior Resident, Department of Skin and VD, Goa Medical College, Bambolim, Goa, India. \\ ${ }^{3}$ Assistant Professor, Department of Skin and VD, Goa Medical College, Bambolim, Goa, India.
}

ABSTRACT

\section{BACKGROUND}

Superficial dermatophytoses are among the most common public health problems in tropical countries like India and account for nearly half the cases in dermatology clinics. A recent increase in number of recalcitrant or resistant dermatophytosis may probably be due to microbiological resistance, improper usage of antifungal agents in inadequate dosage, over the counter use of combination creams. This can have social, psychological, and economic impact on the patients. This study was conducted to assess the impact of dermatophytosis on the patient's Quality of Life using the Dermatology Life Quality Index (DLQI) and to analyse its relationship with various parameters like age, sex, type of tinea, extent of involvement, duration and recurrence.

\section{MATERIALS AND METHODS}

Patients with clinically diagnosed cutaneous dermatophytosis visiting dermatology OPD of Goa Medical College over a period of 3 months were included. Dermatology Life Quality Index( DLQI ) questionnaire was used and correlated with age, sex, duration of symptoms, site and extent of involvement, history of topical applications, past history of similar lesions, and family history, to analyse the impact of dermatophytosis on the quality of life.

\section{RESULTS}

The study showed a definite impact of dermatophytosis on the quality of life with a mean DLQI of $10.84 \pm 5.83$. A majority of patients $(43.57 \%)$ had a very large effect on quality of life. Patients with tinea faciei had the highest impairment of quality of life. The highest score (2.07) was seen for question 1 relating to symptoms and feelings.

\section{CONCLUSION}

This study found a significant impact of dermatophytosis on quality of life. A statistically significant number of patients had a very large effect on the quality of life $(p=0.04)$. Hence, this study emphasizes the need for increasing awareness, early detection and appropriate treatment of dermatophyte infections in order to prevent the spread and eliminate the use of topical steroids in dermatophytosis.

\section{KEY WORDS}

Dermatophytosis, DLQI, Superficial Fungal Infections

HOW TO CITE THIS ARTICLE: Khanvte A, Faleiro K, Pai V. Analysis of dermatology life quality index in dermatophytosis. J. Evolution Med. Dent. Sci. 2019;8(12):915-918, DOI: 10.14260/jemds/2019/203

\section{BACKGROUND}

Superficial dermatophytoses affecting skin, hair and nail are caused by keratinophilic filamentous fungi called dermatophytes. They are classified into three genera: Trichophyton, Microsporum and Epidermophyton. They are the commonest cause of superficial fungal infections worldwide and are more prevalent in hot and humid climates. ${ }^{1}$

Despite the huge prevalence of dermatophytosis there is scarcity of research on impact of dermatophytosis on the quality of life. The itching, discomfort, embarrassment, reduced self-esteem, impediment of work and social activities can lead to significant morbidity. Hence there is a need to assess the extent of impairment of quality of life in these patients using scientific measures.

'Financial or Other Competing Interest': None.

Submission 10-01-2019, Peer Review 06-03-2019,

Acceptance 13-03-2019, Published 25-03-2019.

Corresponding Author:

Dr. Karla Faleiro,

Department of Skin and VD,

Goa Medical College,

Bambolim-403202, Goa, India.

E-mail: karla_faleiro@yahoo.co.in

DOI: $10.14260 /$ jemds $/ 2019 / 203$

\section{(c) $(\mathrm{i}) \Theta$}

Dermatology life quality index questionnaire is a sensitive tool, widely used to assess changes in health-related quality of life. ${ }^{2}$

\begin{abstract}
Aims and Objectives
This study was conducted to assess the impact of dermatophytosis on the patient's Quality of life using the dermatology life quality index (DLQI) and to analyse its relationship with various parameters like age, sex, type of Tinea, extent of involvement, duration and recurrence.
\end{abstract}

\section{MATERIALS AND METHODS}

The study was a hospital based observational cross sectional one done in dermatology OPD of Goa Medical College and Hospital in over a period of 3 months after approval by the institutional ethics committee. A total of 101 patients aged 10 years and above with clinical diagnosis of cutaneous dermatophytosis were included in the study. Patients with hair and nail dermatophyte infections and those unable to comprehend the DLQI questionnaire were excluded.

Details of demographic data, duration of symptoms, site and extent of involvement, history of topical applications, past history of similar lesions, and family history were documented on a specially prepared proforma. A thorough 
dermatological examination was done, and patients were asked to fill the Dermatology Life Quality Index (DLQI) questionnaire.

DLQI is a validated questionnaire which grades quality of life based on following parameters: a) Symptoms and Feelings (Questions 1 and 2), b) daily activities (Questions 3 and 4), c) Leisure (Question 5 and 6), d) Work and School (Question 7), e) Personal relationships (Questions 8 and 9), and f)Treatment(Question 10). Each question is scored as "very much" (score 3), "a lot" (score 2), "a little" (score 1) and "not at all" (score 0) based on problems faced in the last one week. The sum of these scores gives the final DLQI score.

The interpretation is as follows

0-1 : No effect.

2-5: Small effect.

6-10: Moderate effect.

11-20: Very large effect.

21-30: Extremely large effect.

The DLQI scores were analysed and correlated with the various parameters recorded on the proforma.

\begin{tabular}{|c|c|c|c|c|c|c|c|}
\hline Type of Tinea & $\begin{array}{c}\text { No } \\
\text { Effect }\end{array}$ & $\begin{array}{l}\text { Small } \\
\text { Effect }\end{array}$ & $\begin{array}{c}\text { Moderate } \\
\text { Effect }\end{array}$ & $\begin{array}{l}\text { Very } \\
\text { Large } \\
\text { Effect }\end{array}$ & \begin{tabular}{|c|} 
Extremely \\
Large \\
Effect
\end{tabular} & $\begin{array}{c}\text { Total } \\
\text { No. of } \\
\text { Patients }\end{array}$ & $\begin{array}{c}\text { p Value } \\
\text { (n) }\end{array}$ \\
\hline Tinea Cruris & 1 & 3 & 8 & 10 & 2 & 24 & \multirow{12}{*}{0.04} \\
\hline Tinea Corporis & 1 & 1 & 4 & 5 & 0 & 11 & \\
\hline Tinea Corporis + Tinea Cruris & 0 & 9 & 13 & 18 & 2 & 42 & \\
\hline Tinea Faciei & 0 & 0 & 0 & 1 & 0 & 1 & \\
\hline Tinea Faciei + Tinea Corporis & 0 & 1 & 0 & 1 & 0 & 2 & \\
\hline Tinea Faciei + Tinea Cruris & 0 & 0 & 2 & 3 & 1 & 6 & \\
\hline Tinea Corporis+ Tinea Cruris + Tinea Faciei & 1 & 0 & 4 & 4 & 0 & 9 & \\
\hline Tinea Manuum & 0 & 0 & 0 & 1 & 0 & 1 & \\
\hline Tinea Manuum + Tinea Cruris & 0 & 0 & 1 & 0 & 0 & 1 & \\
\hline Tinea Pedis+ Tinea Corporis & 0 & 0 & 1 & 0 & 0 & 1 & \\
\hline Tinea Pedis +Tinea Corporis +Tinea Cruris & 0 & 1 & 1 & 1 & 0 & 3 & \\
\hline Total & 3 & 15 & 34 & 44 & 5 & 101 & \\
\hline \multicolumn{8}{|c|}{ Table 1. Frequency Distribution of Patients Based on DLQI Scores with Respect to Type of Tinea } \\
\hline \multicolumn{8}{|c|}{$\mathrm{n}=$ number of patients in each group based on interpretation of DLQI } \\
\hline
\end{tabular}

Elevated DLQI scores were seen in 100 of the 101 patients with very large effect (score 11-20) being the commonest (43.57\%). A statistically significant number of patients had a very large effect on the quality of life $(\mathrm{p}=0.04)$. Among the patients with Tinea cruris, $41.66 \%$ had a very large effect on quality of life. In the group with Tinea corporis, $45.45 \%$ patients had a very large effect on quality of life.

\section{Statistical Analysis}

Student $\mathrm{t}$ test and one way ANOVA test were used for statistical analysis and $p$ value of $<0.05$ was taken to be significant.

\section{RESULTS}

A total of 101 patients were included in the study with male to female ratio of $1.10: 1$. Mean age of the study population was $32.75 \pm 11.04$ years. The majority $(42.57 \%)$ of patients had a combination of Tinea corporis and Tinea cruris. Family history of tinea was present in 49 (48.51\%) patients. History of topical application of a steroid containing preparation was confirmed in $26 \%$ of the patients. A further $17 \%$ were unaware of the contents of the topical applied. History of recurrence (Developing new lesions following complete clearance in the past) was seen in $40(39.60 \%)$ patients. Generalized involvement (More than one anatomical site) was seen in $64(63.37 \%)$ patients.

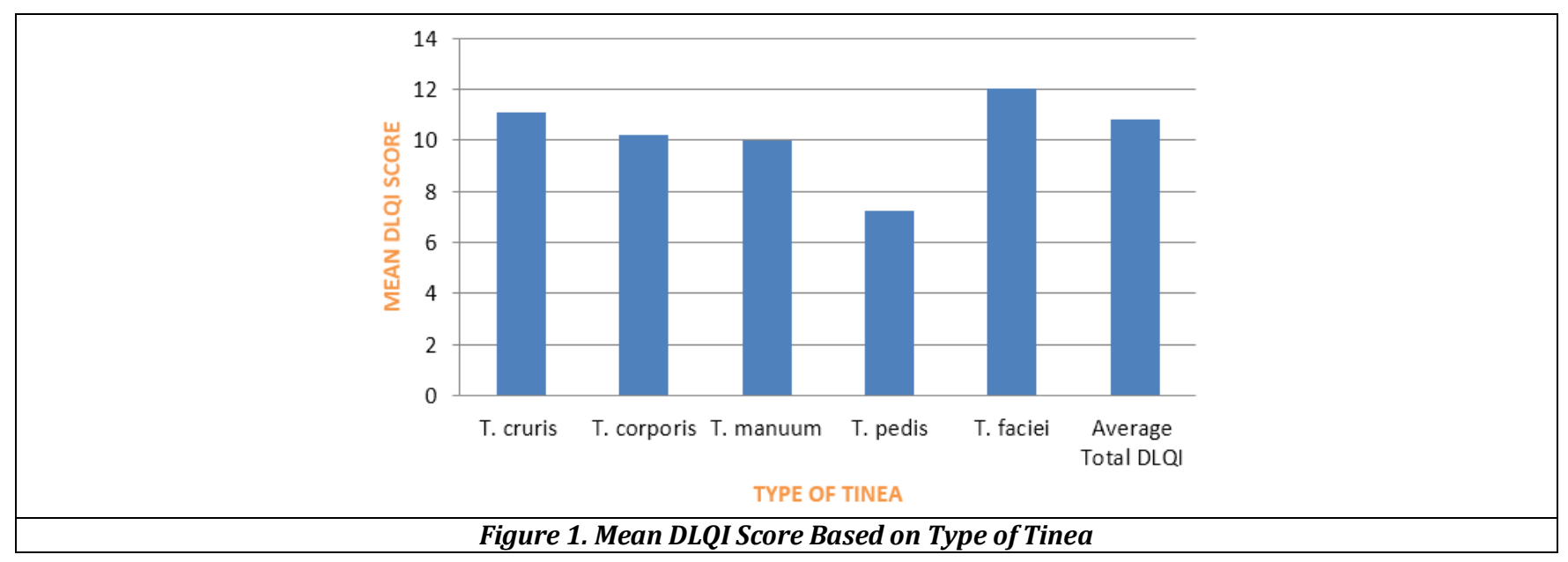

The highest mean DLQI score was seen in patients with T. faciei $(12.05 \pm 5.96)$ in comparison with the mean total DLQI which was $10.84 \pm 5.83$. Correlation between DLQI scores for $\mathrm{T}$. cruris, T. corporis and T. faciei using one-way ANOVA test was not statistically significant ( $\mathrm{p}$ value of 0.428 ). 


\begin{tabular}{|c|c|c|c|c|c|c|c|c|c|}
\hline Parameter & Value & $\begin{array}{c}\text { No } \\
\text { Effect }\end{array}$ & $\begin{array}{l}\text { Small } \\
\text { Effect }\end{array}$ & $\begin{array}{l}\text { Moderate } \\
\text { Effect }\end{array}$ & $\begin{array}{c}\text { Very Large } \\
\text { Effect }\end{array}$ & $\begin{array}{c}\text { Extremely } \\
\text { Large } \\
\text { Effect }\end{array}$ & $\begin{array}{c}\text { Total No. of } \\
\text { Patients }\end{array}$ & $\begin{array}{l}\text { Mean DLQI } \\
\text { Score }\end{array}$ & $\begin{array}{c}\text { p Value } \\
\text { (mean } \\
\text { DLQI) }\end{array}$ \\
\hline \multirow[t]{6}{*}{ Age } & $11--20$ & 0 & 4 & 4 & 7 & 0 & 15 & $10.6 \pm 5.31$ & \multirow{6}{*}{0.059} \\
\hline & $21-30$ & 0 & 2 & 8 & 12 & 2 & 24 & $12.29 \pm 6.40$ & \\
\hline & $31-40$ & 1 & 4 & 13 & 21 & 3 & 42 & $11.73 \pm 5.79$ & \\
\hline & $41-50$ & 1 & 4 & 5 & 3 & 0 & 13 & $7.86 \pm 4.56$ & \\
\hline & $51-60$ & 1 & 1 & 4 & 1 & 0 & 7 & $7.14 \pm 4.48$ & \\
\hline & Total No. of Patients & 3 & 15 & 34 & 44 & 5 & 101 & & \\
\hline \multirow[t]{3}{*}{ Sex } & Males & 2 & 9 & 19 & 20 & 3 & 53 & $10.30 \pm 6.07$ & \multirow{3}{*}{0.165} \\
\hline & Females & 1 & 6 & 15 & 24 & 2 & 48 & $11.43 \pm 5.55$ & \\
\hline & Total No. of Patients & 3 & 15 & 34 & 44 & 5 & 101 & & \\
\hline \multirow[t]{5}{*}{ Duration } & $<1$ Month & 1 & 5 & 2 & 4 & 1 & 13 & $10.38 \pm 8.60$ & \multirow{5}{*}{0.129} \\
\hline & 1-3 Months & 1 & 4 & 17 & 21 & 1 & 44 & $10.2 \pm 4.67$ & \\
\hline & 3-6 Months & 1 & 4 & 11 & 6 & 1 & 23 & $9.95 \pm 5.79$ & \\
\hline & $>6$ Months & 0 & 2 & 4 & 12 & 2 & 20 & $13.6 \pm 5.67$ & \\
\hline & Total No. of Patients & 3 & 15 & 34 & 44 & 5 & 101 & & \\
\hline
\end{tabular}

It was noted that $50 \%$ of the patients in each of the age group of 21-30 and 31-40 yrs had a very large effect on the quality of life. Among the patients in the 11-20 age group, $46.66 \%$ had a very large effect. A greater proportion of females were noted to have a very large effect on quality of life as compared to males (50\% v/s $37.73 \%)$. Among the patients with Tinea of $>6$ months duration, $60 \%$ had a very large effect on the quality of life compared to $47.73 \%$ of patients with Tinea of 1-3-month duration.

The highest mean DLQI score was seen in the 21-30 age group $(12.29 \pm 6.40)$. The lowest mean DLQI score was found in the age group of $51-60$ (7.14 \pm 4.48$)$. Correlation using oneway ANOVA test found a p value of 0.059 . Female patients had a higher mean DLQI score $(11.43 \pm 5.55)$ as compared to males (10.30 \pm 6.07). However, the difference was not statistically significant ( $\mathrm{p}$ value $=0.165$ ).

Patients with duration of Tinea for more than 6 months had the highest mean DLQI score $(13.6 \pm 5.67)$. There was no statistically significant difference noted between the duration of Tinea and DLQI score, using one-way ANOVA test ( $\mathrm{p}$ value= 0.129). Patients having a history of recurrence had a higher mean DLQI $(11.2 \pm 5.85)$ in comparison with patients without history of recurrence $(10.3 \pm 5.84)$. However, this difference was not significant ( $\mathrm{p}$ value $=0.215$ ). Patients who had localized involvement of the body had a higher mean DLQI $(11.02 \pm 5.90)$ than patients with a generalized involvement (10.73 \pm .5 .83). However, this difference was not statistically significant $(\mathrm{p}$ value $=0.404)$.

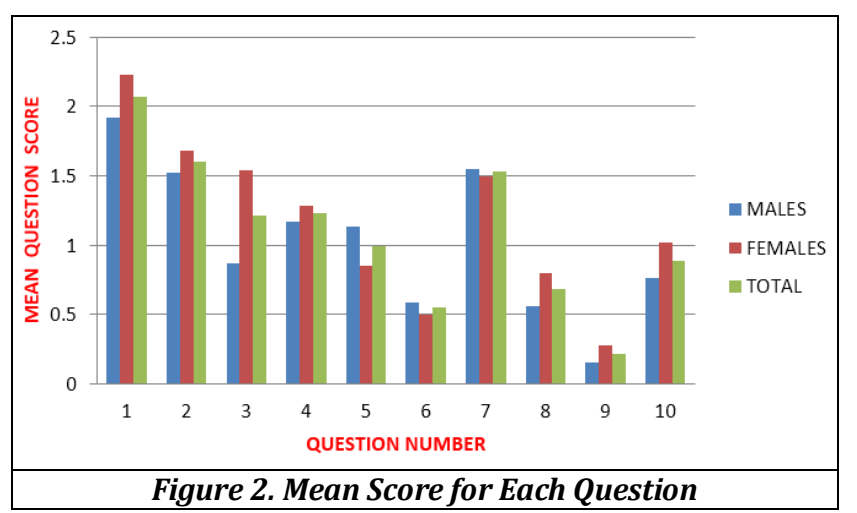

Question 1 (Symptoms and feelings) had the highest mean question score and question 9 (Personal relationships) had the lowest score. The mean score was found to be higher in females compared to males for questions $1,2,3,4,8,9$ and 10 (relating to symptoms and feelings, daily activities, personal relationships and treatment). Questions 5, 6, 7 (Relating to leisure, work and school) had a higher mean score in males.

\section{DISCUSSION}

The study included 101 cases of cutaneous dermatophytosis and was done over a period of 1 month. Highest number of cases were in the age group of $31-40$ years $(41.58 \%)$, followed by age group of 21-30 years (23.76\%). This was in accordance with previous studies. 3,4 A slight male preponderance was found, with a male to female ratio of 1.10:1. This is in accordance with other studies. ${ }^{3}$ Some studies have reported a higher prevalence in females. ${ }^{5}$

A combination of Tinea cruris with Tinea corporis was the most common clinical type, followed by isolated Tinea cruris and isolated Tinea corporis. Similar findings were reported by Peerapur et al.6 Majority of the patients (63.37\%) had generalized involvement (involvement of more than one anatomical site). Higher number of patients (43.56\%) had lesions for a duration of 1-3 months. Kumar et al. had found the duration of symptoms to be greater than 3 months in $53.3 \%$ of the patients, $1-3$ months in $33.7 \%$ cases and less than 1 month in $13 \%$ of the cases. Recurrence was noted in $39.60 \%$ patients. Of these $33.33 \%$ patients had a family history of tinea. Transmission in these cases may be due to direct spread or through fomites. ${ }^{3}$

History of steroid application was found in $26 \%$ of the patients. Most commonly applied steroid preparation was found to be a combination of clobetasol propionate, ofloxacin, ornidazole and terbinafine hydrochloride.

The study showed a definite impact of dermatophytosis on the quality of life with an average DLQI of 10.84. A majority of patients (43.57\%) had a very large effect on quality of life. Patients with tinea faciei had the highest impairment of quality of life. In comparison, study by D'Souza 


\section{Jemds.com}

et al found that patients with tinea cruris had the highest impairment of quality of life. 5 The highest score (2.07) was seen for question 1 (symptoms and feelings). This was similar to the study by D'Souza et al. ${ }^{5}$

\section{CONCLUSION}

This study found a significant impact of dermatophytosis on quality of life. A statistically significant number of patients had a very large effect on the quality of life $(p=0.04)$. Majority of patients complained of moderate to severe itching and embarrassment. There was no statistically significant difference in the DLQI scores based on age, sex, duration, extent of involvement or recurrence. Hence this study emphasizes the need for increasing awareness, early detection and appropriate treatment of dermatophyte infections in order to prevent the spread and eliminate the use of topical steroids.

\section{REFERENCES}

[1] Cdos Tejada S, Mendoza-Sassi RA, Almeida HL Jr, et al. Impact on the quality of life of dermatological patients in southern Brazil. A Bras Dermatol 2011;86(6):111321.

\section{Original Research Article}

[2] Finlay AY, Khan GK. Dermatology Life Quality Index (DLQI) - a simple practical measure for routine clinical use. Clin Exp Dermatol 1994;19(3):210-6.

[3] Mahajan S, Tilak R, Kaushal SK, et al. Clinicomycological study of dermatophytic infections and their sensitivity to antifungal drugs in a tertiary care center. Indian J Dermatol Venereol Leprol 2017;83(4):436-40.

[4] Ansar A, Farschchian M, Nazeri H, et al. Clinicoepidemiological and mycological aspects of tinea incognito in Iran: a 16-year study. Med Mycol J 2011;52(1):25-32.

[5] D'Souza MJ, Hundi KG. Awareness of risk factors for dermatophytoses and its impact on quality of life among adults in Mangalore. A cross-sectional study. IOSR-JDMS 2018;17(6):64-70.

[6] Peerapur BV, Inamdar AC, Pushpa PV, et al. Clinico mycological study of dermatophytosis in Bijapur. Indian J Med Microbiol 2004;22(4):273-4. 